\title{
Domestic Violence and Post-traumatic Stress Disorder Among Women in Ekiti State, Nigeria
}

\author{
Eloh,Modupe Mary \\ College of Health Sciences and Technology, Ijero Ekiti, Ekiti State, Nigeria \\ Akindutire, Isaac Olusola \\ Ekiti State University, Ado Ekiti, Ekiti State, Nigeria
}

\begin{abstract}
Prior studies have shown that women who experience domestic violence are at higher risk of developing posttraumatic stress disorder (PTSD) but this had not been clearly observed among women in Ekiti State. This study investigated domestic violence and PTSD with the purpose of finding out strategies that could help in reducing the occurrences. The study was a descriptive research of the survey type. The sample consisted of 2100 women in Ekiti State. The sample was selected through Multistage sampling procedure. An adapted close-ended questionnaire was used to measure the variables investigated. Face and content validity of the instrument were ensured. Construct validity yielded a correlation coefficient of 0.81 . Reliability of the instrument was ensured and a coefficient of 0.85 obtained. Research questions were answered descriptively and hypotheses were tested using Pearson's Product Moment Correlation Coefficient at 0.05 level of significance.Findings showed that $37.9 \%$ women experienced physical violence, $40.8 \%$ experienced sexual violence and $43 \%$ experienced psychological violence in Ekiti State. Further finding showed $44.3 \%$ of women in Ekiti State exhibited symptoms of posttraumatic stress disorder. Education of children and young people to achieving generational change in violent behaviour was the most preferred strategy in preventing domestic violence among women in Ekiti State. There was significant relationship between physical, sexual and psychological violence, and post-traumatic stress disorder among women in Ekiti State.Healthy relationship education targeted at disrupting the developmental pathways towards domestic violence should be developed and implemented in health education curriculum, at primary and secondary school levels.
\end{abstract}

Keywords: domestic violence; post-traumatic stress disorder; prevention; strategies; women

DOI: $10.7176 / \mathrm{JHMN} / 71-04$

Publication date: February $29^{\text {th }} 2020$

\section{Introduction}

Domestic violence is a life-threatening problem that may primarily affect women and girls. Domestic violence may be exhibited in different forms, such as, physical assault, sexual assault, emotional abuse, rape, molestation, battering, corporal punishment, deprivation of rights and traditional practices that are harmful to women. It often has serious long-term consequences for the individuals involved, their families, communities, and society at large. Domestic violence against women is now recognized as a problem of global magnitude, owing to its detrimental consequences on the health, social and economic welfare of women and their children (World Health Organisation (WHO), 2010).

Domestic violence has been defined by WHO (1997), as the range of sexually, psychologically and physically coercive acts used against adult and adolescent women by current or former male intimate partners. Existing literature suggest that physical, sexual and psychological violence co-exist. Physical violence may often be accompanied by sexual violence, and likely to be accompanied by psychological violence. Physical violence involves being pushed or shoved, slapped or having objects thrown at the victim, being kicked, beaten or dragged. Sexual violence includes unwelcome touches in erogenous zones, attempted rape, being raped and embarrassed by unwanted sexual jokes or comments, while psychological violence involves being criticized and publicly embarrassed, verbally insulted and threatened or experiencing demeaning remarks (WHO, 2012). Women who experience domestic violence may suffer a range of health problems and their ability to participate in public life may diminish. This could also impoverish women and their families.

Global estimates (WHO, 2017), indicated that about 1 in $3(35 \%)$ of women worldwide have experienced either physical and/or sexual violence and most of these violence were perpetrated by intimate partners. This report further stated that worldwide, almost one third (30\%) of women who have been in a relationship report that they have experienced some form of physical and/or sexual violence by their intimate partner in their lifetime. World Health Organization (2016) also made the submission that globally, as many as $38 \%$ of murders of women, are committed by a male intimate partner. It appears that women in Africa, like their counterparts all over the world, suffer domestic violence irrespective of their age, class, religion or social status. Nigeria also has her own fair share, as domestic violence is widespread and seems to be on the increase. According to the 2013 reports of the Center for Law Enforcement Education Foundation (CLEEN, 2013) on the survey of domestic violence in Nigeria, 
1 in every 3 respondents admitted to have been a victim of domestic violence. The survey also found a nationwide increase in domestic violence from $21 \%$ in 2011 to $30 \%$ in 2013.

There have been reports of cases of husbands battering, killing and maiming their wives in the media. These aroused the interest of the researcher in finding out strategies that may be helpful in reducing cases of domestic violence which is still being practiced among Nigerians in an alarming rate. In Ekiti State, it was reported that a 42 year-old man beat his wife to death for denying him sex in Erio-Ekiti (Punch, 2016). Recently, a man residing in Ilasa-Ekiti, beheaded his betrothed wife for not coming to spend the Eld-el-Fitr holiday with him (Punch, 2019). Reacting to the issue of domestic violence, the wife of the Ekiti state Governor, Erelu Bisi Fayemi, lamented that this trend is increasing and becoming worrisome (Daily Trust, 2019). These are compelling evidences that domestic violence against women is a complex public health issue, with far-reaching consequences.

Domestic violence may have serious, lasting and harmful effects on individuals, families, and communities. Women who experience domestic violence may be at considerable risk of developing post-traumatic stress disorder. Wang, Chang, Yang, Du and Shen (2016) found a strong correlation between domestic violence and PostTraumatic Stress Disorder (PTSD). They found out that women who suffered from domestic violence had higher risk of PTSD than those who never experienced domestic violence. According to WHO (2016), domestic violence can lead to depression, post-traumatic stress and other anxiety disorders, sleep difficulties, eating disorders, and suicide attempts. Post-traumatic stress disorder develops in some people who have experienced a shocking, scary or dangerous event which often leaves the victim living in constant fear, pains and depression. In severe cases, it can erode a woman's sense of self-worth and can be incredibly harmful to overall mental and physical well-being. It also lowers the general soundness and fitness of the victim's performance and productivity (National Institute of Mental Health, 2018).

The diagnostic criteria for post-traumatic stress disorder include a history of exposure to a traumatic event that meets specific stipulations and symptoms from each of four symptom clusters: intrusion, avoidance, negative alterations in cognitions and mood, and alterations in arousal and reactivity (American Psychiatric Association, 2013). Post-traumatic stress disorder is diagnosed after a person experiences symptoms for at least one month following a traumatic event. However, symptoms may not appear until several months or even years later. The diagnosis occurs most commonly as a stressful reaction to a catastrophic event involving actual or threatened death or injury. Symptoms of PTSD include increased physiological arousal, persistent re-experiencing of the trauma, trouble sleeping, irritability, and psychic numbing, including dissociation. Behavioural changes after experiencing a traumatic event include fear or anxiety, sadness or depression, guilt and shame, anger and irritability, and negative coping mechanisms such as substance abuse (United States Department of Veterans Affairs, 2012).

Based on the researcher's observations and interactions with few women who shared their experience of domestic violence, some of them tend to show some observable symptoms indicative of post-traumatic stress disorder. Hence, these symptoms may interfere with their daily lives and can cause problems in a relationship, at work, during social interactions, or when trying to accomplish everyday tasks. A considerable body of research has demonstrated that women who are abused by their male intimate partners are at substantially elevated risk for the development of post-traumatic stress disorder and while data is readily available in developed countries, there seems to be scarcity in developing countries. Also, even today, it appears that lack of reliable and continuous data is an obstacle to forming a clear picture of domestic violence against women. Thus, there is need for this study because recent data on prevalence of domestic violence in Ekiti State are not readily available and the degree of relationship between physical, sexual and psychological violence and post-traumatic stress disorder has not been clearly observed among women in Ekiti State.

\section{Statement of the Problem}

As observed by the researcher in Ekiti state, women are beaten, tortured, raped and even murdered by spouses for the most absurd reasons but these violent occurrences are seen as family matters. Therefore, women suffer in silence, as the crime of domestic violence is often shrouded in shame and denial, while as victims, their psychological and physical health are compromised.

The psyche of the Ekiti woman is nurtured over time to believe that a woman should endure whatever she experiences in the hand of the husband, especially for the sake of the children and protection of family reputation. This sermon seems to be what has been built up over the years, and gets passed on through generations, as a norm or sacred culture in which divorce is seen not to be an option, as marriage has been termed to be "for better, for worse". This is seen by the researcher, as the foundation of the mental enslavement most women who continuously put up with domestic violence are made to live with. As a consequence of this, many of the victims tend to be entrapped in domestic violent situations through power and control, traumatic bonding to the abuser, cultural acceptance and fear for safety.

The impact of physical, sexual and psychological violence appears to have resulted in injuries or psychological conditions among women in Ekiti State. The manifestations of physical violence range from minor cuts and abrasions, to lethal blunt and penetrating wounds. Sexual and psychological violence tend to lead to a 
variety of problems, such as low self-esteem, disturbed patterns of eating and sleeping, lack of confidence, depression, self-harm and suicide attempts. More importantly, the experience of psychological disorders such as post-traumatic stress disorder often leaves the victim living in constant fear, pains and depression, and may erode a victim's sense of self-worth and also lower the general soundness and fitness of the victim's performance and productivity. Despite efforts at eliminating domestic violence at national and state levels, the problem seems to have continued to escalate. Therefore, this study was designed, to investigate domestic violence and post-traumatic stress disorder among women in Ekiti State and to find out strategies that can be helpful in preventing domestic violence.

\section{Purpose of the Study}

The purpose of this study was to:

i. $\quad$ find out if women in Ekiti State exhibit symptoms of post-traumatic stress disorder

ii. identify the relationship between domestic violence and post-traumatic stress disorder among women in Ekiti State; and

iii. find out the strategies that may prevent domestic violence among women in Ekiti State.

\section{Research Questions}

The following research questions were raised and answered for the study:

1. Do women in Ekiti State exhibit symptoms of post-traumatic stress disorder?

2. What strategy can be helpful in preventing domestic violence among women in Ekiti State?

\section{Research Hypotheses}

The following research hypotheses were formulated and tested for the study:

1. There is no significant relationship between physical violence and post-traumatic stress disorder among women in Ekiti State.

2. There is no significant relationship between sexual violence and post-traumatic stress disorder among women in Ekiti State.

3. There is no significant relationship between psychological violence and post-traumatic stress disorder among women in Ekiti State.

\section{Significance of the Study}

This study would be significant in revealing the correlation between physical, sexual and psychological violence to post-traumatic stress disorder. The findings of this study would have relevance to women, young girls, husbands, parents, teachers, health educators, counsellors, social welfare, government and interested researchers. This study would be useful to women in making relevant decisions on issues relating to domestic violence and women who are victims of domestic violence might become aware of symptoms and management of post-traumatic stress disorder.

The findings might assist policy makers in the health and education sectors to embark on awareness programs on domestic violence and post-traumatic stress disorder and also develop teaching models for attitudinal change that would reduce the occurrence of domestic violence among women. It could assist major stakeholders in planning of health education programs and formulation of policies and also in implementation of strategies that can be helpful in the prevention of domestic violence.

\section{Methodology}

The study was a descriptive research design of the survey type. The survey design was adopted because it made it possible to collect information from a large representative sample of the entire women population in Ekiti State and enabled the researcher to observe, describe and interpret the prevailing phenomena associated with domestic violence and post-traumatic stress disorder among women in Ekiti state. The population for this study comprised of all women in Ekiti State with an estimate of 1,183,470 (National Population Commission, 2006). The sample for this study consisted of 2100 women aged 15 and above in Ekiti State. The sample was selected through Multistage sampling procedure. The instrument for this study was a close-ended structured questionnaire. The instrument for measuring domestic violence was adapted from the compendium of Assessment Tools for Measuring Intimate Partner Violence Victimization and Perpetration, Center for Disease Control and Prevention, Atlanta, (2006) and the instrument for measuring Post-traumatic Stress Disorder (PTSD) was self-structured based on four categories of PTSD symptoms from Diagnostic and statistical manual of mental disorders by American Psychiatric Association (2013). The instrument was subjected to face, content and construct validity measures. Construct validity of the instrument was further ensured using convergent validity measure. The constructed questionnaire on Domestic Violence and Post-traumatic Stress Disorder (DVPTSDQ) and another standardized related instrument on Psychometric Properties of the Post-traumatic Diagnostic (PPPD) Scale for DSM-5 
constructed by Foa et al. (2015) were administered to 20 women in Ondo State. Thereafter, the scores of the two instruments were correlated using Pearson's Product Moment Correlation. A correlation coefficient of 0.81 was obtained which was considered positive and high enough. The reliability of the instrument was determined by administering the instrument once on 20 women randomly selected in Ondo State. The scores from administered questionnaire were analysed using Cronbach's alpha reliability analysis. A coefficient of 0.845 was obtained which indicated that the instrument had good internal consistency and was adequate for the study. Copies of the questionnaire were administered on 2100 respondents in their place of residence. Twelve research assistants, who were trained on the subject matter as well as modalities and the procedures to follow in the administration of the instrument, were employed to assist the researcher in the administration of the instrument. Both descriptive and inferential statistics were used to analyse the data. The research questions were answered with the descriptive statistics of frequency counts, percentages, mean and bar chart. Hypotheses were tested using Pearson's Product Moment Correlation analysis at 0.05 level of significance.

Limitation: The researcher was unable to retrieve 45 copies of the questionnaire, some of which were not properly filled, and thus cancelled. Notwithstanding, this did not affect the result of this study as the instrument return rate was $97.9 \%$.

\section{Results and Discussion}

Question 1: Do women in Ekiti State exhibit symptoms of post-traumatic stress disorder?

910 respondents representing $44.3 \%$ indicated to have exhibited symptoms of post-traumatic stress disorder while 1145 representing $55.7 \%$ did not exhibit symptoms of post-traumatic stress disorder. Therefore, the mean score of the responses 20.64 was used to categorize the respondents into those who exhibited symptoms of post-traumatic stress disorder and those who did not. Respondents who scored below the mean score were categorized into nonexperience of post-traumatic stress disorder while those with scores equal to or above the mean score were categorized into experience of post-traumatic stress disorder symptoms. The result is presented in Table 1.

Table 1: Symptoms of Post-traumatic Stress Disorder Exhibited by Women in Ekiti State

\begin{tabular}{|c|c|c|c|c|c|c|c|}
\hline $\mathbf{S} / \mathbf{N}$ & ITEMS & $\mathbf{F}$ & $\mathbf{S}$ & $\mathbf{R}$ & $\mathbf{N}$ & MEAN & RANK \\
\hline 19. & $\begin{array}{l}\text { I have experienced a life- threatening } \\
\text { event that caused intense fear of my } \\
\text { partner }\end{array}$ & $\begin{array}{l}397 \\
(19.3 \%)\end{array}$ & $\begin{array}{l}396 \\
(19.3 \%)\end{array}$ & $\begin{array}{l}374 \\
(18.2 \%)\end{array}$ & $\begin{array}{l}888 \\
(43.2 \%)\end{array}$ & 2.15 & $1^{\text {st }}$ \\
\hline 20. & $\begin{array}{l}\text { I have repeated, disturbing } \\
\text { memories, and images of a stressful } \\
\text { experience from my relationship } \\
\text { with my partner }\end{array}$ & $\begin{array}{l}324 \\
(15.8 \%)\end{array}$ & $\begin{array}{l}477 \\
(23.2 \%)\end{array}$ & $\begin{array}{l}335 \\
(16.3 \%)\end{array}$ & $\begin{array}{l}919 \\
(44.7 \%)\end{array}$ & 2.10 & $3^{\text {rd }}$ \\
\hline 21. & $\begin{array}{l}\text { I avoid thoughts, feelings or physical } \\
\text { sensations that bring up memories of } \\
\text { the negative events that happened } \\
\text { between me and my partner }\end{array}$ & $\begin{array}{l}327 \\
(15.9 \%)\end{array}$ & $\begin{array}{l}473 \\
(23 \%)\end{array}$ & $\begin{array}{l}433 \\
(21.1 \%)\end{array}$ & $\begin{array}{l}822 \\
(40 \%)\end{array}$ & 2.15 & $1^{\text {st }}$ \\
\hline 22. & $\begin{array}{l}\text { I feel irritable as demonstrated in } \\
\text { angry outbursts as a result of the } \\
\text { stressful experience between me and } \\
\text { my partner }\end{array}$ & $\begin{array}{l}295 \\
(14.4 \%)\end{array}$ & $\begin{array}{l}451 \\
(21.9 \%)\end{array}$ & $\begin{array}{l}427 \\
(20.8 \%)\end{array}$ & $\begin{array}{l}882 \\
(42.9 \%)\end{array}$ & 2.08 & $4^{\text {th }}$ \\
\hline 23. & $\begin{array}{l}\text { I lose interest in significant activities } \\
\text { of my life due to my husband's } \\
\text { behaviour }\end{array}$ & $\begin{array}{l}286 \\
(13.9 \%)\end{array}$ & $\begin{array}{l}442 \\
(21.5 \%)\end{array}$ & $\begin{array}{l}413 \\
(20.1 \%)\end{array}$ & $\begin{array}{l}914 \\
(44.5 \%)\end{array}$ & 2.05 & $5^{\text {th }}$ \\
\hline 24. & $\begin{array}{l}\text { I feel cut-off from other people by } \\
\text { my partner }\end{array}$ & $\begin{array}{l}286 \\
(13.9 \%)\end{array}$ & $\begin{array}{l}428 \\
(20.8 \%)\end{array}$ & $\begin{array}{l}391 \\
(19 \%)\end{array}$ & $\begin{array}{l}950 \\
(46.2 \%)\end{array}$ & 2.02 & $7^{\text {th }}$ \\
\hline 25. & $\begin{array}{l}\text { I find it difficult to sleep due to the } \\
\text { stressful experience I have with my } \\
\text { partner }\end{array}$ & $\begin{array}{l}311 \\
(15.1 \%)\end{array}$ & $\begin{array}{l}430 \\
(20.9 \%)\end{array}$ & $\begin{array}{l}368 \\
(17.9 \%)\end{array}$ & $\begin{array}{l}946 \\
(46 \%)\end{array}$ & 2.05 & $5^{\text {th }}$ \\
\hline 26. & $\begin{array}{l}\text { I have problems concentrating on } \\
\text { important matters due to such } \\
\text { experience }\end{array}$ & $\begin{array}{l}302 \\
(14.7 \%)\end{array}$ & $\begin{array}{l}428 \\
(20.8 \%)\end{array}$ & $\begin{array}{l}340 \\
(16.5 \%)\end{array}$ & $\begin{array}{l}985 \\
(47.9 \%)\end{array}$ & 2.02 & $7^{\text {th }}$ \\
\hline 27. & $\begin{array}{l}\text { I have problem eating regularly due } \\
\text { to such experience }\end{array}$ & $\begin{array}{l}297 \\
(14.5 \%)\end{array}$ & $\begin{array}{l}411 \\
(20 \%)\end{array}$ & $\begin{array}{l}356 \\
(17.3 \%)\end{array}$ & $\begin{array}{l}991 \\
(48.2 \%)\end{array}$ & 2.01 & $9^{\text {th }}$ \\
\hline 28. & $\begin{array}{l}\text { I feel on guard, watchful and fearful } \\
\text { because of what my partner might do }\end{array}$ & $\begin{array}{l}326 \\
(15.9 \%)\end{array}$ & $\begin{array}{l}392 \\
(19.1 \%)\end{array}$ & $\begin{array}{l}323 \\
(15.7 \%)\end{array}$ & $\begin{array}{l}1014 \\
(49.3 \%)\end{array}$ & 2.01 & $9^{\text {th }}$ \\
\hline
\end{tabular}

F-Frequently, S-Sometimes, R-Rarely, N-Never

Question 2: What strategy can be helpful in preventing domestic violence among women in Ekiti State? 
Using a cut-off mean score of 2.50 for the rating scale, all the items had mean scores above the cut-off point. This implies that education of children and young people to achieving generational change in violent behaviour; a major shift in community attitude and behavior toward domestic violence through health education; counselling the victims and perpetrators against domestic violence; ensuring justice system that will guarantee victims safety and hold perpetrators to account; speaking out against domestic violence and seeking help through social support system are strategies can be helpful in preventing domestic violence among women in Ekiti State. The result is presented in Table 2.

Table 2: Strategies for Preventing Domestic Violence Among Women in Ekiti State

\begin{tabular}{|l|l|l|l|l|l|l|}
\hline S/N & ITEMS & SA & A & D & SD & MEAN \\
\hline 29. & $\begin{array}{l}\text { Education of children and young people to } \\
\text { achieving generational change in violent } \\
\text { behaviour }\end{array}$ & $\begin{array}{l}1289 \\
(62.7 \%)\end{array}$ & $\begin{array}{l}514 \\
(25 \%)\end{array}$ & $\begin{array}{l}89 \\
(4.3 \%)\end{array}$ & $\begin{array}{l}163 \\
(7.9 \%)\end{array}$ & 3.43 \\
\hline 30. & $\begin{array}{l}\text { A major shift in community attitude and } \\
\text { behaviour toward domestic violence through } \\
\text { health education }\end{array}$ & $\begin{array}{l}1216 \\
(59.2 \%)\end{array}$ & $\begin{array}{l}571 \\
(27.8 \%)\end{array}$ & $\begin{array}{l}93 \\
(4.5 \%)\end{array}$ & $\begin{array}{l}175 \\
(8.55)\end{array}$ & 3.38 \\
\hline 31. & $\begin{array}{l}\text { Counselling the victims and perpetrators } \\
\text { against domestic violence }\end{array}$ & $\begin{array}{l}1160 \\
(56.4 \%)\end{array}$ & $\begin{array}{l}609 \\
(29.6 \%)\end{array}$ & $\begin{array}{l}127 \\
(6.2 \%)\end{array}$ & $\begin{array}{l}159 \\
(7.7 \%)\end{array}$ & 3.35 \\
\hline 32. & $\begin{array}{l}\text { A justice system that will ensure victim's } \\
\text { safety and hold perpetrators to account }\end{array}$ & $\begin{array}{l}1136 \\
(55.3 \%)\end{array}$ & $\begin{array}{l}597 \\
(29.1 \%)\end{array}$ & $\begin{array}{l}124 \\
(6 \%)\end{array}$ & $\begin{array}{l}198 \\
(9.6 \%)\end{array}$ & 3.30 \\
\hline 33. & $\begin{array}{l}\text { Speaking out against domestic violence } \\
\text { (through social media, movies etc.) }\end{array}$ & $\begin{array}{l}1127 \\
(54.8 \%)\end{array}$ & $\begin{array}{l}653 \\
(31.8 \%)\end{array}$ & $\begin{array}{l}117 \\
(5.7 \%)\end{array}$ & $\begin{array}{l}158 \\
(7.7 \%)\end{array}$ & 3.34 \\
\hline 34. & $\begin{array}{l}\text { Seeking help through social support system } \\
\text { (e.g. NGO's religious houses etc) }\end{array}$ & $\begin{array}{l}1165 \\
(56.7 \%)\end{array}$ & $\begin{array}{l}605 \\
(29.4 \%)\end{array}$ & $\begin{array}{l}91 \\
(4.4 \%)\end{array}$ & $\begin{array}{l}194 \\
(9.4 \%)\end{array}$ & 3.33 \\
\hline
\end{tabular}

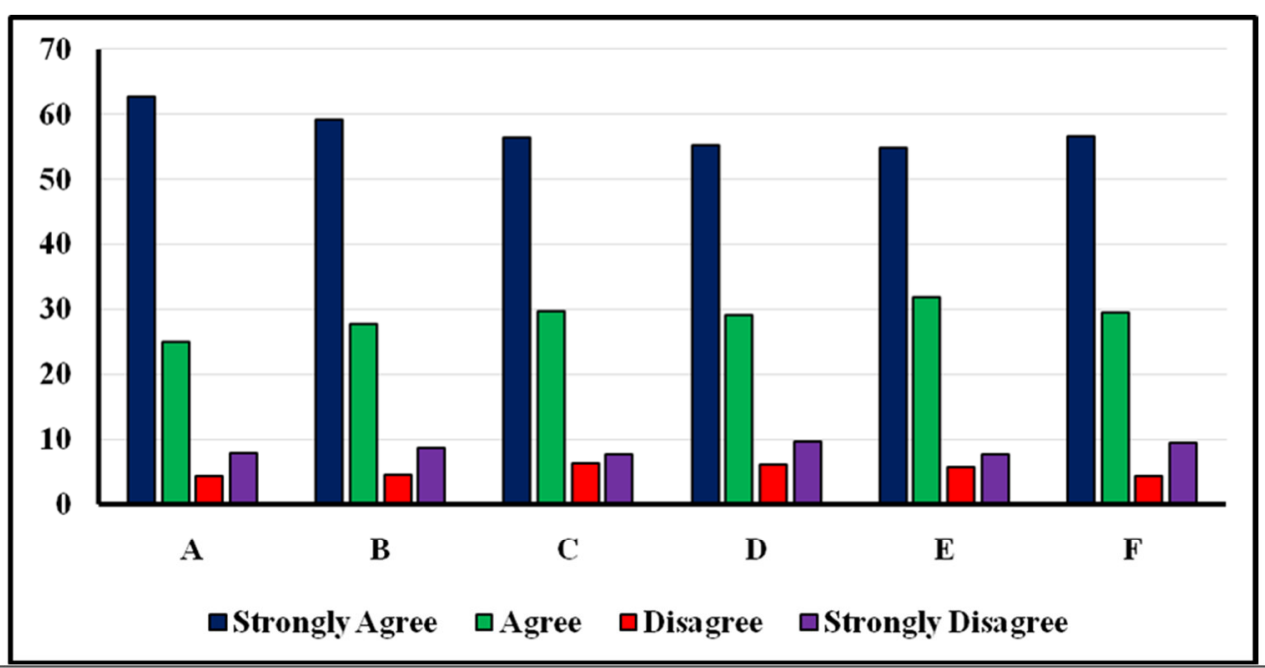

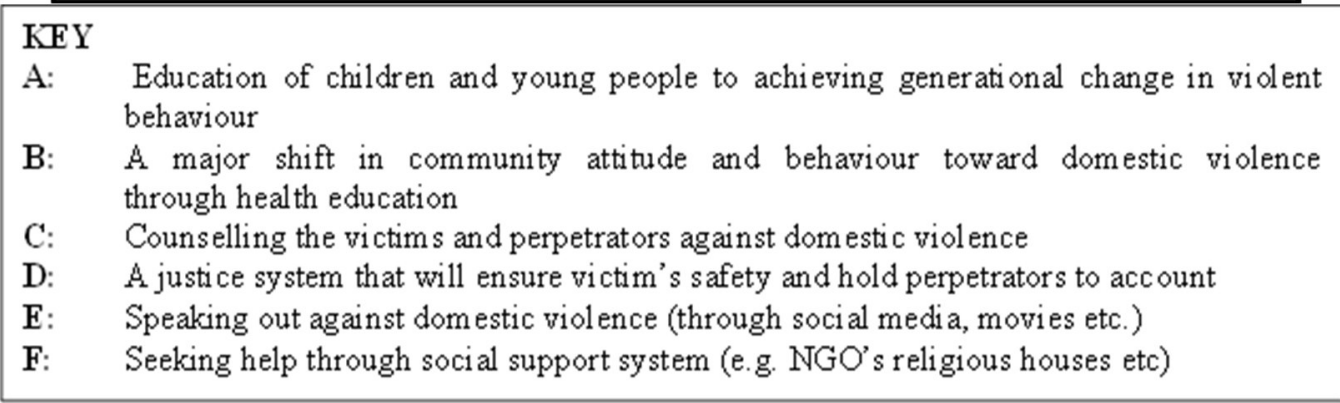

Figure 1: Strategies of Preventing Domestic Violence among Women in Ekiti State

\section{Testing of Hypotheses}

Hypothesis 1: There is no significant relationship between physical violence and post-traumatic stress disorder among women in Ekiti State.

From the sample, 778 (37.9\%) women in Ekiti State who indicated to have experienced physical Violence were correlated. 
Table 3: Physical Violence and Post-traumatic Stress Disorders Among Women in Ekiti State

\begin{tabular}{|l|l|l|l|l|l|}
\hline Variables & $\boldsymbol{N}$ & Mean & $\boldsymbol{S D}$ & $\boldsymbol{r}_{\text {cal }}$ & $\boldsymbol{r}_{\text {table }}$ \\
\hline Physical violence & 778 & 15.13 & 3.47 & & \\
\cline { 1 - 4 } Post- traumatic Stress Disorder & 778 & 27.45 & 8.55 & $0.353^{*}$ & \multirow{2}{*}{0.062} \\
\hline
\end{tabular}
* $p<0.05$

Table 3 shows that $r_{\text {cal }}(0.353)$ is greater than $r_{\text {table }}(0.062)$ at 0.05 level of significance. The null hypothesis is rejected. This implies that there is significant relationship between physical violence and post-traumatic stress disorder among women in Ekiti State. The relationship between physical violence and post-traumatic stress disorder is low, positive and statistically significant at 0.05 level.

Hypothesis 2: There is no significant relationship between sexual violence and post-traumatic stress disorder among women in Ekiti State.

From the sample, $839(40.8 \%)$ women in Ekiti State who indicated to have experienced sexual violence were correlated.

Table 4: Sexual Violence and Post-traumatic Stress Disorders Among Women in Ekiti State

\begin{tabular}{|l|l|l|l|l|l|}
\hline Variables & $\boldsymbol{N}$ & Mean & SD & $\boldsymbol{r}_{\text {cal }}$ & $\boldsymbol{r}_{\text {table }}$ \\
\cline { 1 - 3 } Sexual violence & 839 & 13.68 & 3.25 & & \\
\cline { 1 - 4 } Post- traumatic Stress Disorder & 839 & 26.30 & 8.88 & $0.405^{*}$ & 0.062 \\
\hline
\end{tabular}

* $p<0.05$

Table 4 shows that $r_{\text {cal }}(0.405)$ is greater than $r_{\text {table }}(0.062)$ at 0.05 level of significance. The null hypothesis is rejected. This implies that there is significant relationship between sexual violence and post-traumatic stress disorder among women in Ekiti State. The correlation between sexual violence and post-traumatic stress disorder is moderate, positive and statistically significant at 0.05 level.

Hypothesis 3: There is no significant relationship between psychological violence and post-traumatic stress disorder among women in Ekiti State.

From the sample, 883 (43\%) women in Ekiti State who indicated to have experienced psychological Violence were correlated.

Table 5: Psychological Violence and Post-traumatic Stress Disorders Among Women in Ekiti State

\begin{tabular}{|l|l|l|l|l|l|}
\hline Variables & $\boldsymbol{N}$ & Mean & $\boldsymbol{S D}$ & $\boldsymbol{r}_{\text {cal }}$ & $\boldsymbol{r}_{\text {table }}$ \\
\hline Psychological violence & 883 & 17.39 & 3.62 & & \\
\cline { 1 - 4 } Post-traumatic Stress Disorder & 883 & 26.56 & 8.98 & $0.395^{*}$ & 0.062 \\
\hline
\end{tabular}

\section{"p $<0.05$}

The result in Table 5 shows that $r_{\text {cal }}(0.395)$ is greater than $r_{\text {table }}(0.062)$ at 0.05 level of significance. The null hypothesis is rejected. Therefore, there is significant relationship between psychological violence and posttraumatic stress disorder among women in Ekiti State. The relationship between psychological violence and posttraumatic stress disorder is low, positive and statistically significant at 0.05 level of significance.

\section{Discussion}

A finding showed $44.3 \%$ of women in Ekiti State exhibited symptoms of post-traumatic stress disorder. This study further revealed that, the symptoms of post-traumatic stress disorder exhibited more among women in Ekiti State were; avoiding thoughts, feelings or physical sensations that bring up memories of the traumatic event; having repeated, disturbing memories, and images of a stressful experience from relationship with their partners and feeling irritable as demonstrated in angry outbursts. This finding is consistent with Tagurum et al., (2015) which found out that symptoms of PTSD experienced by their respondents included denial or avoidance of thoughts of the crisis, numbness and detachment from surroundings, thoughts and memories recur, even though the danger has passed, were thought to affect between 7 and $8 \%$ of their population. Symptoms of PTSD seems to be relatively common among victims of domestic violence than those who never experienced domestic violence, as supported by Bisson et al. (2015), whose study revealed lifetime prevalence to be between $1.9 \%$ and $8.8 \%$, but indicated that, the rate doubles in populations affected by conflict and reaches more than $50 \%$ in survivors of domestic violence.

The finding further revealed that education of children and young people to achieving generational change in violent behaviour was the most preferred strategy in preventing domestic violence among women in Ekiti State. This could be due to the fact that, Ekiti indigenes place so much value on education and it is also believed that, teaching safe and healthy relationship skills through empowerment and education approaches attempt to promote social norms that are protective against violence.

A finding showed a significant relationship between physical violence and post-traumatic stress disorder among women in Ekiti State. This implies that women who experience physical violence exhibit symptoms of post-traumatic stress disorder. This finding is in agreement with the findings of Kelly, (2010), who claimed that women who experience physical abuse from intimate partner have an increased risk of developing PTSD symptoms. The finding is in agreement with that of Black et al., (2011), which revealed that physical violence by 
an intimate partner have significant short or long-term effects including posttraumatic stress disorder. The finding of this study contradicts that of Temple, Weston and Rodriguez, (2007) that sexual aggression by a partner is a stronger predictor of negative mental health outcomes than physical abuse.

Another finding revealed a significant relationship between sexual violence and post-traumatic stress disorder among women in Ekiti State. This implies that women who experience sexual violence exhibit symptoms of posttraumatic stress disorder. This finding agrees with Kelly (2010) whose finding, showed that sexual abuse was significantly correlated with total pain symptoms and difficulty sleeping, which are symptoms of posttraumatic stress disorder. This is because having sexual contact without explicit consent goes beyond physical injury to psychological distress. Victims of sexual violence may have increased feelings of irritability, feeling of anger, increased arousal, and numbness among others; which are symptoms of posttraumatic stress disorder.

More finding from this study showed a significant relationship between psychological violence and posttraumatic stress disorder among women in Ekiti State. This implies that women who experience psychological violence exhibit symptoms of post-traumatic stress disorder. This finding is consistent with the finding of Wang et al., (2016) who found that, women who suffered from psychological violence were 5.06 times more likely to suffer from PTSD. This is because psychological abuse has effects on the mind. People who live with and love someone who is emotionally abusive seem to experience trauma on daily basis. The experience of constant putdowns and criticisms, not only wears down self- esteem, but may impact the nervous system in the same way a physical trauma would. The victims may feel isolated and worthless thereby feeling depressed and thoroughly worn out from constantly waiting for the next attack.

\section{Conclusion}

Based on the findings of this study, it could be concluded that:

Women who experience domestic violence (physical, sexual and psychological violence) exhibit symptoms of post-traumatic stress disorder. Hence, there is relationship between domestic violence and post-traumatic stress disorder. Education of children and young people to achieving generational change in violent behavior would be a better strategy in preventing domestic violence among women in Ekiti State.

\section{Recommendations}

Based on the findings of this study, the following recommendations were made:

- Health education campaigns should be pursued vigorously through the mass media, especially radio and television, by airing programs and jingles that would enlighten the general public about post- traumatic stress disorder as a consequence of domestic violence against women.

- Relationship education and other education programs targeted at disrupting the developmental pathways toward partner violence, by breaking the cycle of violence, transforming gender norms which support domestic violence, should be developed and implemented in health education curriculum, at both primary and secondary schools level to achieving generational change in violent behavior.

- Government should provide a battered women shelter, as an element of social support, to serve as a refuge where victims can feel safe and have access to services designed to repair the effects of domestic violence.

- Health educators and other health workers should understand the implication of these findings in order to assist victims of domestic violence to take the right approach in managing domestic violence.

\section{References}

American Psychiatric Association (2013). Diagnostic and statistical manual of mental disorders (5th ed.). Arlington, VA: American Psychiatric Publishing.

Bisson, J.I., Cosgrove, S., Lewis, C. \& Roberts, N.P. (2015). Post-traumatic stress disorder. British Medical Journal, 351: h6161. doi: 10.1136/bmj.h6161

Black, M.C., Basile, K.C., Breiding, M.J., Smith, S.G., Walters, M.L., Merrick, M.T., Chen, J. \& Stevens, M.R. (2011). The National Intimate Partner and Sexual Violence Survey (NISVS): Summary Report. Atlanta, GA: National Center for Injury Prevention and Control, Centers for Disease Control and Prevention.

Center for Disease Control and Prevention, (2006). Measuring Intimate Partner Violence Victimization and Perpetration: A compendium of assessment tools Atlanta (GA).

CLEEN Foundation (2013). National Crime Victimization surveys. Retrieved February 2nd 2018 from https://cleen.org

Foa, E. D., McLean, C.P., Zang, Y., Zhong, J., Powers, M.B., Kauffman, B.Y., Rauch, S., Porter, K. \& Knowles, K.(2016). Psychometric properties of the Posttraumatic Diagnostic Scale for DSM-5 (PDS-5). Psychological Assessment, 28(10),1166-1171.

Kelly, U. A. (2010). Intimate Partner Violence, Physical Health, Posttraumatic Stress Disorder, Depression, and Quality of Life in Latinas. Western Journal Emergency Medicine, 11(3), 247-251.

National Institute of Mental Health (NIMH) (2018). Post-Traumatic Stress Disorder. Retrieved August 10th 2018 
from https://www.nimh.nih.gov/health/topics/post-traumatic-stress-disorder-ptsd/index.shtml

National Population Commission (2006). Ekiti (State, Nigeria) - Population statistics, charts, map and location. Retrieved August 26 ${ }^{\text {th }}, 2019$ from www.citypopulation.de/php/nigeria-admin.php? admlid=NGA013

Punch newspaper (2016, August 11). Man beat wife to death for denying him sex. Retrieved April 22nd 2018 from http//punchng.com

Punch newspaper (2019, June 12). Herdsman allegedly beheads wife in Ekiti. Retrieved July 7th 2019 from http//punchng.com

Tagurum, Y.O., Chirdan, O.O., Obindo, T., Bello, D.A., Afolaranmi, O.T., Hassan, Z.I. \& Yilgwan, C. (2015). Prevalence of Violence and Symptoms of Post-Traumatic Stress Disorder among Victims of Ethno-Religious Conflict in Jos, Nigeria. Journal of Psychiatry, 18, 172-178.

Temple, J.R., Weston, R., Rodriguez, B.F. \& Marshall, L.L. (2007). Differing effects of partner and nonpartner sexual assault on women's mental health. Violence Against Women, 13, 285-297.

United States Department of Veterans Affairs (2012). National Center for PTSD. Understanding PTSD. Retrieved July 4th 2018 from www.ptsd.va.gov

Wang, L.L., Chang, X.N., Yang, S.B., Du, Y.K. \& Shen, M. (2016). Relationship between domestic violence and posttraumatic stress disorder among women living in the communities of Wuhan city. Europe PubMed Central, 37(12), 1574-1577.

World Health Organisation (1997). Violence against women: priority health issue. Geneva. WHO/FRH/WHD/97.8

World Health Organization (2010). Series of briefings on violence prevention: the evidence. Retrieved on $26^{\text {th }}$ June, 2019

from https://www.who.int/violence_injury_prevention/violence/4th_milestones_meeting/evidence_briefings_all.p $d f ? u a=1$

World Health Organization (2012). Understanding and addressing violence against women: intimate partner violence. WHO RHR 12.36 eng. Retrieved May 19th 2018 from http://apps.who.int

World Health Organisation (2016). Violence against women; intimate partner and sexual violence against women fact sheet. Geneva.

World Health Organisation (2017). Violence against women fact sheet. Geneva. Retrieved May 30th 2019 from https://www.who.int/news-room/fact-sheets/detail/violence-against-women 